\title{
Information Reach and Range Impact on Interorganizational Systems Platforms
}

\author{
Ismail M. Romi \\ Faculty of Administrative Sciences and Informatics, Palestine Polytechnic University, Hebron, Palestine \\ Email: ismailr@ppu.edu
}

Received September 26, 2013; revised October 20, 2013; accepted November 18, 2013

Copyright (C) 2014 Ismail M. Romi. This is an open access article distributed under the Creative Commons Attribution License, which permits unrestricted use, distribution, and reproduction in any medium, provided the original work is properly cited. In accordance of the Creative Commons Attribution License all Copyrights ¿ 2014 are reserved for SCIRP and the owner of the intellectual property Ismail M. Romi. All Copyright (C) 2014 are guarded by law and by SCIRP as a guardian.

\section{ABSTRACT}

Organizations tend to use information systems (IS) applications that require data to be exchanged between different parties, while data exchange is restricted with information reach and range, which determines the organizations' IT platform. To determine the best platform, a comparison between electronic data interchange (EDI) and web services was conducted depending on certain criteria, and then matching the results with the information reach and range. The main findings show that the web services platform can take place when the range of information access is required by anyone and anywhere regardless of IT base. EDI can take place when the range of information access doesn't exceed the organizations' boundaries. But when the range of information access exceeds the organizations' boundaries, still between certain partners, web services or EDI can take place, and thus the organization can select them from those platforms depending on other criteria such as security, and cost.

\section{KEYWORDS}

Interorganizational System; IOS Platform; Electronic Data Interchange; Web Services; Information Reach and Range

\section{Introduction}

Most organizations are facing significant pressure to make their operational, tactical, and strategic processes more efficient and effective. Until recently, the main focus of many organizations was on improving internal operations. However, establishing strategic alliances between trading partners along the supply chain through the utilization of IT may result in great benefits [1]. To achieve that organizations collect huge amounts of data, organizations tend to use information systems (IS) applications that require data to be exchanged between different parties such as customer relationship management systems, supply chain management systems, e-business, e-government, and so forth. These large homogeneous and heterogeneous data derive an increased need for interoperability between those sets of parties. Where schemes for data sharing have generally failed in the past because database approaches tend to impose strict global constraints: a single global schema, a globally consistent data in- stance, and central administration [2]. Meanwhile, the information technology platform affects the organization's ability to enjoy its business plans, through restricting the reach and range of its information [3]. However, empirical results concerning the impact of IT platform and data sharing models are inconsistent, and an overall synthesis across the numerous empirical studies seems to be lacked. The main objective of this study is to provide a further insight into the interorganizational system platforms and its impact on data sharing, and then find out the suitable platform for the organizational requirements. Therefore, this study addresses the following questions:

1. What are the interorganizational systems (IOS)?

2. What are the interorganizational systems platforms?

3. What are the determinants of IT platforms?

4. How to select them from those platforms?

To pursue these questions, a comparative review of the prior research will be conducted to find out the most used IT platforms in implementing interorganizational systems, 
and then comparing those platforms, depending on specified criteria in order to find the most suitable one that matches with the organizational infrastructure and improves its performance.

This paper focuses on the determinants of interorganizational systems, and is organized as follows. Section 2 reviews several researches focusing on interorganizational systems, electronic data interchange, web services, and information reach and range. Section 3 presents a comparison between IOS platforms. Section 4 explains the relationship between IOS platforms and information reach and range. The fifth section presents conclusions of this paper, recommendations, and requires future researches.

\section{Background and Literature Review}

\subsection{Interorganizational Systems (IOS)}

An IOS is defined as a network-based information system (IS) that extends beyond traditional enterprise boundaries [4]. Where the Community Health Information Networks defines Interorganizational systems as using information technologies and telecommunications to store, transmit, and transform clinical and financial information. This information can be shared among cooperative and competitive participants, such as payers, hospitals, alternative delivery systems, clinics, physicians, and home health agencies [5]. Ibrahim [6] defines interorganizational systems as automated information systems shared by more than one organization and allowing information flow across organizational boundaries. Where Boonstra and Vries [7] added that, Inter-organizational systems; are systems that cross organizational borders using technological opportunities to enable many businesses to implement electronic networks among suppliers, customers and other business partners. Those systems can be labeled as extra-organizational systems, e-commerce systems, e-business systems, and supply chain management systems. Meanwhile Han et al. [6] defines IOS as is an information system that facilitates the exchange of products, services and information between firms.

The formation of interorganizational networks is driven by several partially overlapping objectives, mainly; risk reduction, economies of scale and/or scope, technology exchanges, co-opting or blocking competition, overcoming government mandated trade or investment barriers, facilitating international expansion and opening new markets, linking complementary contributions of the partners in a value system and achieving of synergy effects [8]. Where Ibrahim [6] find out that IOS can reduce the costs of communications and at the same time extend the possibilities of coordination. Boonstra and Vries [7] add that IOS are aimed at reducing both transaction costs and organization costs of one or more of the companies in- volved in the IOS-relationship. In many cases however, companies also try to achieve market dominance and other strategic interests by means of speeding up the process of data transaction and by implementing IOS to support decision making processes within the company. Hong [4] adds that, with IOS permitting information access to other organizations, the organizational boundary is redefined and extended to the extent that a firm's value chain needs to be redesigned. Therefore, Business organizations increasingly establish electronic links with their competitors or with firms in different industries to gain a competitive advantage.

\subsection{Advancements in Interorganizational Systems}

Barrett and Konsynski [9] classified IOSs on five levels of IOS participation. At level 1, a firm accesses a system that is run and operated by other companies. Level 2 participants design, develop, maintain, and share a single application such as a customer order processing system. Level 3 participants take responsibility for a network in which lower-level participants may share. Level 4 participants develop and share a network with diverse applications that may be used by many different types of participants. At level 5, any number of lower-level participants may be integrated in real time over complex operating environments.

In their literature review; Nagy et al. [10] find out that the field of IOS adoption already has a long history [11]. Most researches focuses on electronic data interchange (EDI). EDI has been used for more than 30 years to exchange structured data electronically in a standardized format between organizations [12,13]. Chwelos et al. [14] has suggested that knowledge obtained from studying IOS adoption could be extended by studying the adoption of internet-based systems that interconnect businesses. Extranets, XML-based messaging and web services carry the promise to drastically reduce switching costs between systems and the cost of integration with legacy systems [15].

\subsection{Electronic Data Interchange (EDI)}

Greif and Sarin [16] define data sharing as a fundamental to computer-supported cooperative work; people share information through explicit communication channels and through their coordinated use of shared database. Where Sarathy and Muralidhar [17] describes data sharing as a fundamental enabler of coordination among supply chain partners. Therefore, data sharing can be defined as the process of interchanging, analyzing, retrieving and integrating data among multiple data sources in a controlled access manner.

Electronic Data Interchange (EDI) can be defined as 
an electronic transmission of standardized business documents between trading partners with little or without human intervention [18,19]. Where, CMS [20] defines EDI as the process of transacting business electronically. It includes submitting claims electronically, or "paperless" claims processing, as well as electronic remittance, Electronic Funds Transfer (EFT) and electronic inquiry [20]. Meanwhile Kim and Lee [21] considered EDI as a form of interorganizational information systems (IOIS), and is a means of telecommunications which makes it possible to electronically exchange information on the communications networks using standardized forms, recognized by to rapid development of Internet-based information technologies computers, when business entities and related institutions exchange documents. Furthermore, EDI stands for the transfer of structured data, by agreed standards from computer application to computer application through electronic means. Where, various industries, governments and financial institutes use it to exchange high volume and dynamic information such as purchase orders, container stowage and financial data [22].

Electronic data interchange (EDI) enables business organizations to efficiently work together, quickly exchanging transaction information in standardized formats [23]. It allows electronic communication of business information with trading partners across a company's borders: it permits organizations to generate electronic purchase orders, invoices, bills of lading and a variety of other documents and sends them instantly to trading partners anywhere in the world, and data security and network reliability concerns [1]. CMS [20] adds that EDI enables faster process, improving cash flow, reducing mailing and administrative costs, better control over data, reducing staff time and cost.

Tullverkit [24] shows that the secure electronic data interchange (EDI) means that the issuer of information can be secured identified, the information is protected against change, and transferred by means of secure communication. Therefore secure EDI communication requires that the electronic document cannot be changed without this being detected, no one shall be able to send the electronic document in someone else's name-deliberately or by mistake-without this being detected, the sender shall not be able to deny having produced and sent the electronic document, the recipient shall not be able to deny having received the electronic document, and no unauthorized person shall be able to read the electronic document.

However, there have been several disadvantages, mainly; EDI is regional, standards are frequently modified, and require expensive transformation software [22, 25], in addition to the additional costs associated with the value added network (VAN) services, establishing EDI between trading partners requires compatible hardware at both ends in order to have seamless processing, and preagreed to standards and protocols are required [1].

\subsection{Web Services}

In their review to Guinard et al. [27] and Wang and Shigo [28]; Yahyaoui et al. [29] states that web services are the technology of choice when developing business applications that need to be loosely coupled, platform independent, and capable to cross-enterprise boundaries. Composition is a cornerstone to this development; it supports web services act together according to a certain business logic, which permits at the end to take over complex users' requests. Web services simplify interoperability and, therefore, application integration. They provide a means for wrapping existing applications so developers can access them through standard languages and protocols [30]. A Web service is a software system designed to support interoperable machine-to-machine interaction over a network. It provides a standard means of interoperating between different software applications, running on a variety of platforms and/or frameworks. A Web service is an abstract notion that must be implemented by a concrete agent. The agent is the concrete piece of software or hardware that sends and receives messages, while the service is the resource characterized by the abstract set of functionality that is provided [31,32].

Meanwhile, web services technologies are a collection of XML technology standards that work together to provide web services capabilities, those technologies includes: XML technologies, SOAP, WSDL, and UDDI. Where; XML technologies are collection of extensible information representation and manipulation technologies [33]. SOAP is an XML-based messaging framework specifically designed for exchanging formatted data across the internet [34]. WSDL technology is a web services description language that describes the messages and types of data used in messages, operations with associated in and out messages, bindings of operations to transports, physical location of service (endpoint) specifications [35]. UDDI technology (universal description, discovery and integration of web services), which is sponsored by the OASIS organization, and supports the ability to register and find services on the internet [36].

Standardization simplifies interoperability: Instead of interacting with heterogeneous systems, each with its own transport protocol, data format, interaction protocol, and the like, applications can interact with systems that are more homogeneous. A standards-based approach helps reduce both development and maintenance costs for integrated systems. More specifically, Web services standards foster support of loosely coupled decentralized interactions [30]. Where, web Services requires physical and operational security processes for network and server 
infrastructure, as well as service specific security implementations. Therefore, secured web services require multiple levels of security (the operating system (OS) of the host platform, the virtual instance OS or guest OS, a firewall, and signed API calls), and service specific security (provides extensive security features to enable you to protect sensitive data and applications) [37]. Internet based information system offers advantages based on the characteristics of the Internet. These advantages are not limited to: internet has one communication standard (TCP/IP) regardless of the industry, reduction in expenses, scalability - the ability of the information systems to accommodate organizational change, low demand for additional technical components, less training for employees, and better chances of adding new trading partners $[1,38]$.

\subsection{Information Reach and Range}

The review by Martin et al. [3] to the study of Keen [39], suggests that the scope of the use of information technology by organization determined by three features, mainly information technology platform, information reach, and information range. Where information technology platform is the set of hardware, software, and standards an organization uses to build information sysems; this platform influences the services that an organization can deliver to the market.

Information reach shows how the internal and external stakeholders can access information through an organiza- tion's IT platform. Information range shows the information and information-based services that can be directly shared through an organization's IT platform.

IT platform is determined by the information reach and range dimensions. Where information reach is determined by the authorized access to the organizations' information, thus information reach can be from the inside or outside the organization. Meanwhile, information range dimension is limited by the amount and degree of service sharing through the IT platform, thus, information range is determined by standard messages, stored data, and organization transactions. Figure 1 shows the interaction between information reach and range dimensions, which determines the required IT platform, and thus, restricts organizations' in implanting business models.

\section{A Comparison between IOS Platforms}

Table 1 provides a comparison between EDI and Web Services. This comparison takes into consideration the medium, business partners, data sharing, platform, cost, and security.

As a result of the comparison (Table 1), implementing EDI requires organizations to have compatible platforms, and coordinating the use of shared databases and transactions. Meanwhile web services can be implemented regardless of platform type, and provides a standard means of interoperating between different software applications.

EDI requires value added networks, thus it is secured,

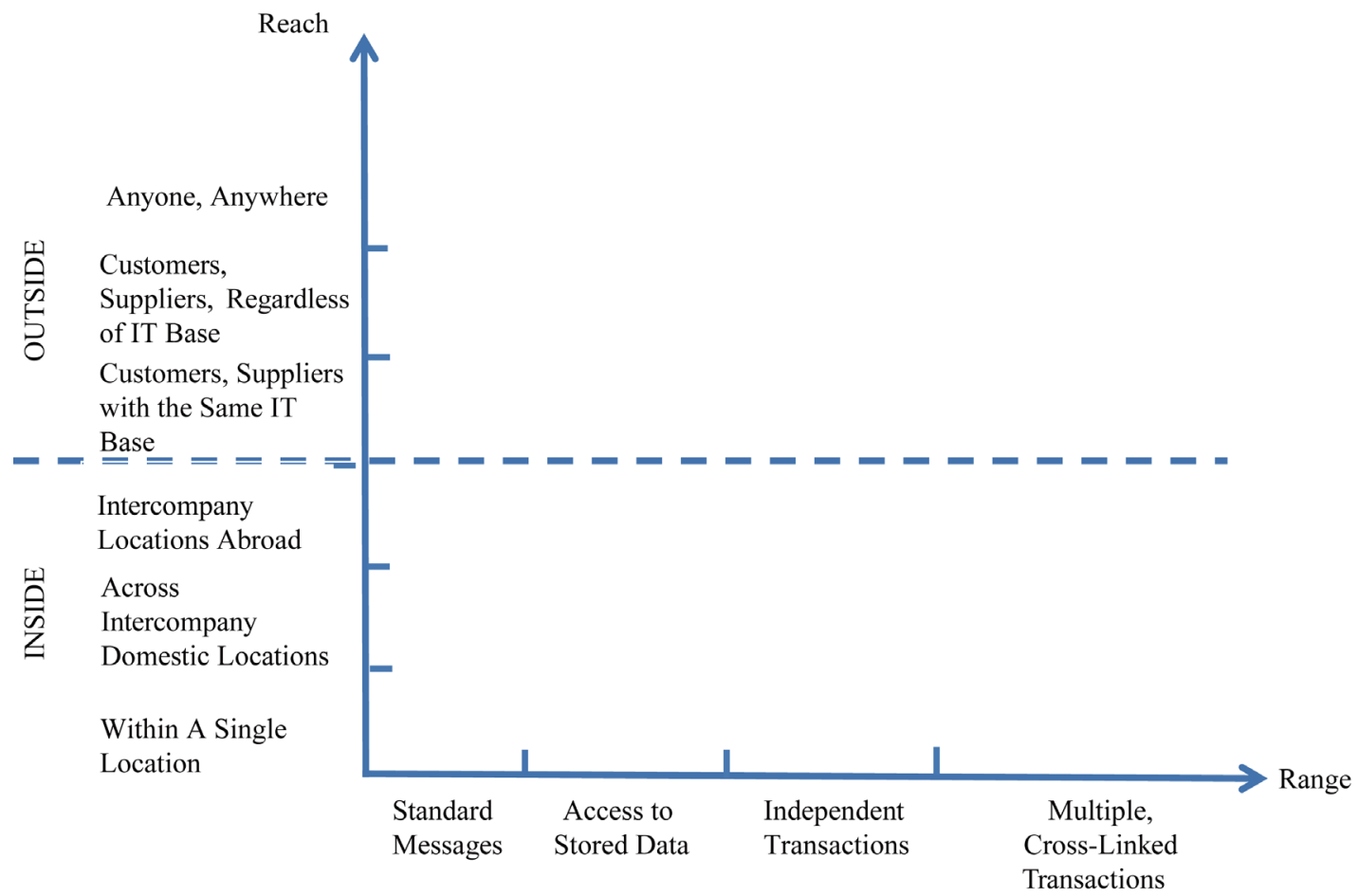

Figure 1. Dimensions of reach and range supported by IT platform. Source: Martin et al. [3]. 
and expensive, therefore; it is regional. While web services can be conducted using the Internet, thus it reduces the expenses, and becomes universal, while it requires complex security aspects.

\section{IOS Platforms, and Information Reach and Range}

Interorganizational Systems can be configured in various ways; they can be set up as one-to-one (a typical buyerseller system), one-to-many (a marketing or purchasing system), or many-to-many (electronic markets), depending on the interaction patterns between the participants [4]. Where, reach and range of the IT-Platform affects the degree of freedom a firm enjoys its business plans. Therefore, the organization has to decide its business model, and then select the best platform that enables to achieve the selected business model, taking into consid- eration cost, and security issues.

Figure 2 shows the situations where web services or EDI can take place, depending on the comparison criteria in Table 1, and information reach and range. Web services platform can take place when the range of information access is required by anyone and anywhere regardless of IT base. Where, EDI can take place when the range of information access doesn't exceed the organizations boundaries. Meanwhile, when the range of information access exceeds the organizations' boundaries, but still between certain partners, then web services or EDI can take place, in this case the organization have to select between those platforms depending on another criteria's such as; cost, security, and so forth.

\section{Conclusion and Recommendations}

This study reviews literature related to interorganizational

Table 1. A comparison between EDI and web services.

\begin{tabular}{lll}
\hline Criteria & Electronic Data Interchange & Web Services \\
\hline Medium & Value-added network (VAN) & Internet connection \\
Communication & Computer-computer & Computer-computer, computer-human \\
Scope & Suites regional connections & Universal \\
Sharing & $\begin{array}{l}\text { Coordinated use of shared database, exchanging transaction } \\
\text { information in standardized formats }\end{array}$ & $\begin{array}{l}\text { Provides a standard means of interoperating between different } \\
\text { software applications }\end{array}$ \\
Platform & The same platform & $\begin{array}{l}\text { Running on a variety of platforms and/or frameworks. } \\
\text { Cost }\end{array}$ \\
& $\begin{array}{l}\text { Expensive transformation software, and the cost of VAN } \\
\text { services }\end{array}$ & $\begin{array}{l}\text { Reduced expenses (the use of internet, low demand for } \\
\text { additional technical aspects). }\end{array}$ \\
Security & $\begin{array}{l}\text { Information is protected against change, and transferred by } \\
\text { means of secure communication }\end{array}$ & $\begin{array}{l}\text { Requires physical and operational security processes for network } \\
\text { and server infrastructure, as well as service specific security } \\
\text { implementations. }\end{array}$ \\
\hline
\end{tabular}

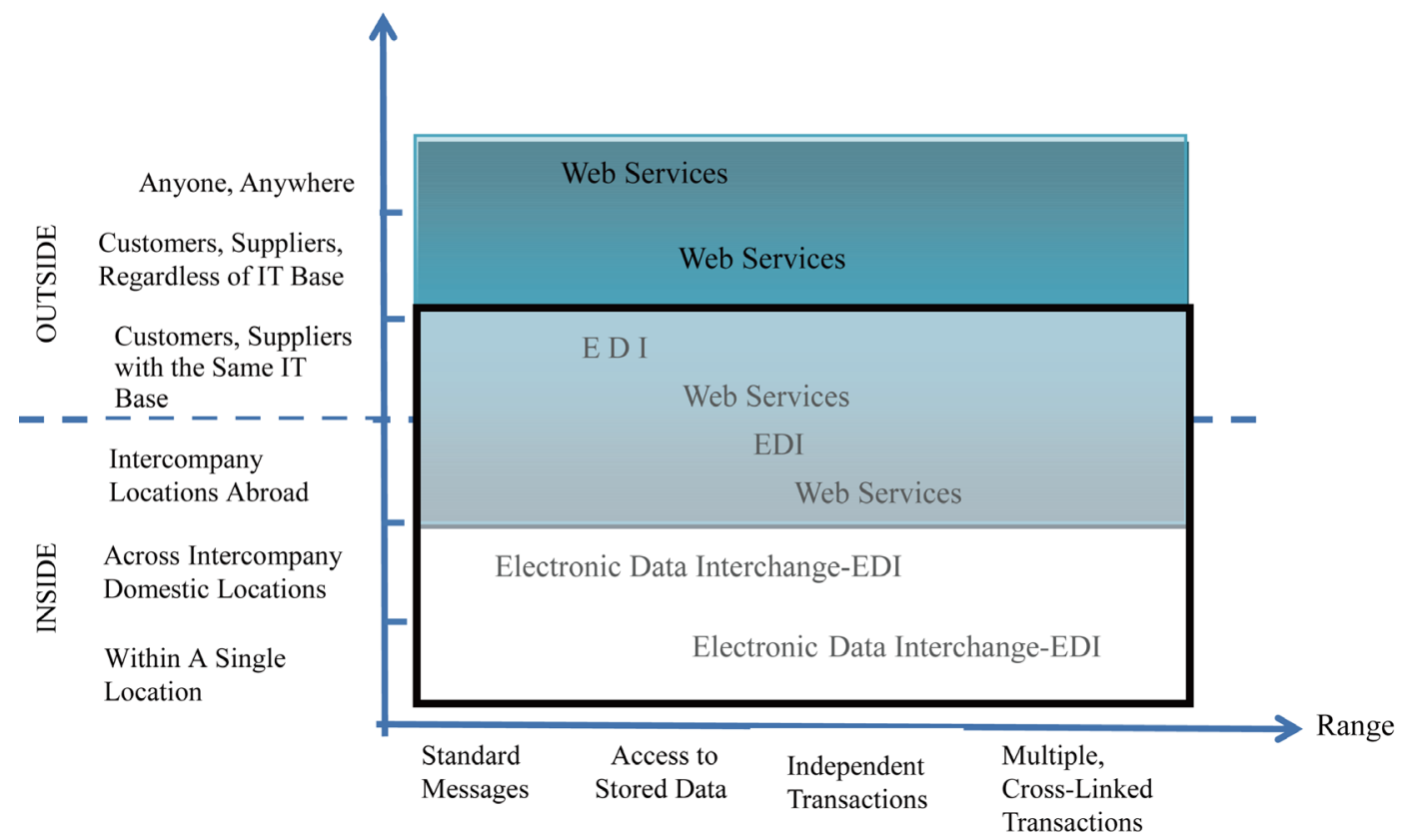

Figure 2. IOS platform \& information reach and range. 
systems platforms, mainly EDI and web services, and then compares those platforms depending on certain criteria, besides information reach and range. The main findings can be summarized in the following points:

- Web services platform can take place when the range of information access is required by anyone and anywhere regardless of IT base.

- EDI can take place when the range of information access doesn't exceed the organizations boundaries.

- When the range of information access exceeds the organizations boundaries, but still between certain partners, web services or EDI can take place.

Further researches are required to test the situation when the organizations have to select them between web services and EDI.

This article is an extended version of the paper presented at the International Conference on Information \& Intelligent Sysyems-ICIIS'2013, Tunisia, March 24-26, 2013.

\section{REFERENCES}

[1] K. S. Soliman and B. D. Janz, “An Exploratory Study to Identify the Critical Factors Affecting the Decision to Establish Internet-Based Interorganizational Information Systems,” Information \& Management, Vol. 41, No. 6, 2004, pp. 697-706. http://dx.doi.org/10.1016/j.im.2003.06.001

[2] T. J. Green, G. Karvounarakis, N. E. Taylor, O. Biton and Z. G. Ives, "Orchestra: Facilitating Collaborative Data Sharing," International Conference on the Management of Data, University of Pennsylvania, 2007.

[3] E. W. Martin, D. W. Dehayes, J. A. Hoffer and W. C. Perkins, "Managing Information Technology," Prentice Hall, 2002.

[4] I. B. Hong, "A New Framework for Interorganizational Systems Based on the Linkage of Participants' Roles," Information \& Management, Vol. 39, No. 4, 2002, pp. 261270. http://dx.doi.org/10.1016/S0378-7206(01)00095-7

[5] F. C. Payton, "Lessons Learned from Three Interorganizational Health Care Information Systems," Information and Management, Vol. 37, No. 1, 2000, pp. 311-321. http://dx.doi.org/10.1016/S0378-7206(99)00057-9

[6] M. K. M. Ibrahim, "Interorganizational Systems from Different Perspectives," Conference of Information Science (Infwet 03), 2003.

[7] A. Boonstra and J. Vries, "Analyzing Inter-Organizational Systems from a Power and Interest Perspective,” International Journal of Information Management, Vol. 25, No. 6, 2005, pp. 485-501. http://dx.doi.org/10.1016/j.ijinfomgt.2005.08.006

[8] P. S. Ring and A. H. Van de Ven, "Structuring Cooperative Relationships between Organizations," Strategic Management Journal, Vol. 13, No. 7, 1992, pp. 483-498. http://dx.doi.org/10.1002/smj.4250130702

[9] S. Barret and B. R. Konsynski, "Inter-Organizational In- formation Sharing Systems,” MIS Quarterly, 1982, pp. 93-105. http://dx.doi.org/10.2307/248993

[10] A. Nagy, B. Orriens and A. M. Fairchild, "The Promise and Reality of Internet Based Interorganizational Systems, IADIS International Conference e-Society, 2004.

[11] R. Somasundaram and J. Rose, "Rationalizing, Probing, Understanding: The Evolution of the Inter-Organizational Systems Adoption Field,” 36th Annual Hawaii International Conference on System Sciences (HICCS-36), 2003.

[12] G. Stefansson, "Business-to-Business Data Sharing: A Source for Integration of Supply Chains,” International Journal of Production Economics, Vol. 75, No. 1-2, 2002, pp. 135-146.

http://dx.doi.org/10.1016/S0925-5273(01)00187-6

[13] R. O’Callaghan and J. A. Turner, "Electronic Data Interchange-Concepts and Issues,” Stern School of Business, New York University, 1995.

[14] P. Chwelos, I. Benbasat and A. S. Dexter, "Research Report: Empirical Test of an EDI Adoption Model," Information Systems Research, Vol. 12, No. 3, 2001, pp. 304321. http://dx.doi.org/10.1287/isre.12.3.304.9708

[15] M. P. Papazoglou, P. M. Ribbers and A. Tsalagtidou, "Integrated Value Chains and Their Implications from a Business and Technology Standpoint," Decision Support Systems, Vol. 29, No. 4, 2000, pp. 323-342.

http://dx.doi.org/10.1016/S0167-9236(00)00081-6

[16] I. Greif and K. S. Sunil, "Data Sharing in Group Work," ACM Transactions on Office Information Systems, Vol. 5, No. 2, 1987, pp. 187-211.

http://dx.doi.org/10.1145/27636.27640

[17] R. Sarathy and K. Muralidhar, "Secure and Useful Data Sharing,” Decision Support Systems, Vol. 42, No. 1, 2006, pp. 204-220. http://dx.doi.org/10.1016/j.dss.2004.10.013

[18] E. W. T. Ngai and A. Gunasekaran, "Implementation of EDI in Honk Kong: An Empirical Analysis,” Industrial Management and Data System, Vol. 104, No. 1, 2004, pp. 88-100. http://dx.doi.org/10.1108/02635570410514124

[19] P. Y. K. Chua and C. C. F. Jim, "Adoption of Electronic Data Interchange in Small and Medium Sized Enterprises," Journal of Global Information Management, Vol. 10, No. 4, 2002, pp. 61-85. http://dx.doi.org/10.4018/jgim.2002100104

[20] CMS, "Electronic Data Interchange (EDI)," American Medical Association, 2009.

[21] B. G. Kim and S. Lee, "Factors Affecting the Implementation of Electronic Data Interchange in Korea," Computers in Human Behavior, Vol. 24, No. 2, 2008, pp. 263283. http://dx.doi.org/10.1016/j.chb.2006.11.002

[22] The Facilitation Committee, "Revised IMO Compendium on Facilitation and Electronic Business, International Maritime Organization, FAL.5/Circ 40,” 2013.

[23] F. Kaefer and E. Bendoly, "The Adoption of Electronic Data Interchange: A Model and Practical Tool for Managers,” Decision Support Systems, Vol. 30, No. 1, 2000, pp. 23-32. http://dx.doi.org/10.1016/S0167-9236(00)00087-7

[24] Tullverket, "Guidelines and Instructions on Security for Electronic Data Interchange (EDI) Version 2.0 EN 2011- 
06-23,” 2011. http://www.tullverket.se

[25] J. Nurmilaaksom, "Edi, xml and E-Business Frameworks: A Survey,” Computers in Industry, Vol. 59, No. 4, 2007, pp. 370-379. http://dx.doi.org/10.1016/j.compind.2007.09.004

[26] I. M. Romi, "Interface Design Factors Impact on Core Affect," Journal of Emerging Trends in Engineering and Applied Sciences (JETEAS), Vol. 3, No. 2, 2012, pp. 373382.

[27] D. Guinard, V. Trifa, S. Karnouskos, P. Spiess and D. Savio, "Interacting with the soa-based internet of things: Discovery, query, selection, and on-demand provisioning of web services," IEEE Transactions on Services Computing, Vol. 3, No. 3, 2010, pp. 223-235.

[28] Q. Wang and O. Shigo, "Web Services Composition by I/O Data Structure Correspondences," Software Engineering Conference, APSEC'09, Asia-Pacific, 2009, pp. 135142.

[29] H. Yahyaoui, Z. Maamar, E. Lim and P. Thiran, "Towards a Community-Based, Social Network-Driven Framework for Web Services Management,” Future Generation Computer Systems, 2013. http://dx.doi.org/10.1016/j.future.2013.02.003

[30] H. R. Nezhad, B. Benatallah, F. C. Casati and F. Toumani, "Web Services Interoperability Specifications," IEEE Computer Society, 2006, pp. 24-32.

[31] W3C, "Web Services Architecture,” 2004.
http://www.w3.org/TR/ws-arch/\#id2281505

[32] D. Lee, J. Kwon, S. Lee, S. Park and B. Hong, "Scalable and Efficient Web Services Composition Based on a Relational Database,” Journal of Systems and Software, Vol. 84, No. 12, 2011, pp. 2139-2155. http://dx.doi.org/10.1016/j.jss.2011.05.068

[33] W3C, “Extensible Markup Language (XML),” 2003. http://www.w3.org/XML/

[34] W3C, “SOAP Version 1.2,” 2004. http://www.w3.org/TR/soap/

[35] W3C, "Web Services Description Language (WSDL) 1.1," 2001. http://www.w3.org/TR/wsdl

[36] OASIS, “UDDI in a Web Services World,” 2006. http://uddi.xml.org/uddi-101

[37] Amazon, “Amazon Web Services: Overview of Security Processes,” 2013. http://aws.amazon.com/security

[38] I. M Romi, I. Awad and M. Elkordy, “A Model of Organizational Politics Impact on Information Systems Success,” International Joint Conferences on Computer, Information, and Systems Sciences, and Engineering, Bridgeport University, 2008.

[39] P. G. W. Keen, "Relevance and Rigor in Information Systems Research: Improving Quality, Confidence, Cohesion and Impact in Information Systems Research,” Contemporary Approaches and Emergent Traditions, 1991, pp. 27-49. 